\title{
Influence of non-/low plastic fines on cone penetration and liquefaction resistance
}

\author{
Nurhan Ecemis *, Mustafa Karaman \\ Department of Civil Engineering, Izmir Institute of Technology, Urla, Izmir 35430, Turkey
}

\section{A R T I C L E I N F O}

\section{Article history:}

Received 31 March 2014

Received in revised form 10 July 2014

Accepted 12 August 2014

Available online 23 August 2014

\section{Keywords:}

Liquefaction resistance

Cone penetration resistance

Clean sand

Coefficient of consolidation

Relative density

Sand with fines

\begin{abstract}
A B S T R A C T
Uncertainties prevail at the current liquefaction screening method based on the cone penetration test (CPT) as to whether the existence of fines increases liquefaction resistance or decrease cone penetration resistance. In this study, field-based data are used to evaluate the effects of non-/low plastic fines on liquefaction resistance at the current CPT-based liquefaction assessment method. The first part of this paper examines the effects of the coefficient of consolidation or drainage characteristics of soils containing fines on cone penetration resistance. The coefficient of consolidation is influenced by the fines content and the relative density of the soil. The second part of this paper investigates the contribution of fines content less than $30 \%$ by weight on the liquefaction resistance of soils at different relative densities. Fines content over $30 \%$ by weight and/or high plasticity of fines can cause additional complications; therefore, it needs different valuation methods, which is beyond the scope of this paper. The liquefaction resistance of sands and silty sands is reinterpreted from the current CPT-based liquefaction assessment method. The trend, which presents the change of liquefaction resistance with fines content at the same relative density, is compared with the available laboratory-based data in the literature. The results show that the interpreted trend is not consistent with the laboratory-based correlations obtained by several previous researchers. Therefore, there will be probably some inaccuracies in estimation of liquefaction potential of silty sand using the current CPT-based liquefaction assessment method.
\end{abstract}

(c) 2014 Elsevier B.V. All rights reserved.

\section{Introduction}

Liquefaction is a devastating phenomenon by which loose saturated granular soils temporarily lose their shear strength during an earthquake as a result of the loss of particle contact and the development of excess pore pressures (Seed, 1976). Over the past four decades, since the liquefaction phenomenon was first explained, most research (Seed, 1976; Finn et al., 1971; Casagrande, 1975; Castro, 1975; Lee, 1976) has focused on clean sands (fines content less than 5\%). However, as case study information has come to light, it is apparent that non-/low plastic silty sands and in some cases even silts, are frequently involved in liquefaction (Bray and Sancio, 2006; Idriss and Boulanger, 2008). As summarized in the state-of-practice paper by Youd et al. (2001), several in-situ tests are commonly used for the direct evaluation of the liquefaction potential of sandy soils, including the standard penetration test (SPT), cone penetration test (CPT or CPTu for piezocone penetration), and shear wave velocity test $\left(V_{s}\right)$. The cone penetration test has gained worldwide attention because it can provide a continuous or near continuous profile, and it is rapid, repeatable, reliable, and cost effective when compared to the other field tests (Lunne et al., 1997; Mayne, 2007; Shuttle and Cunning, 2007). However, despite its appeal,

\footnotetext{
* Corresponding author. Tel.: +90232750 6812; fax: +902327506801.

E-mail address: nurhanecemis@iyte.edu.tr (N. Ecemis).
}

the effect of fines content on the cone penetration resistance and cyclic resistance is not well understood. Also, the quantification of effects of fines on liquefaction resistance is difficult, and one encounters the problem of establishing a proper basis for comparison of sands containing fines and clean sand.

To facilitate the usage of the CPT in liquefaction analyses, numerous researchers have proposed relationships between liquefaction resistance and CPT measurements (Stark and Olson, 1995; Robertson and Wride, 1998; Juang et al., 1999; Carraro et al., 2003; Huang et al., 2005; Kokusho et al., 2005; Cai et al., 2012). Huang et al. (2005) performed a series of cone penetration chamber tests and cyclic triaxial tests on two different sand specimens with various fines contents and densities. The cyclic resistance ratio (CRR) was measured using stress-controlled cyclic triaxial tests when the soil specimens were consolidated under an isotropic effective confining stress of $100 \mathrm{kPa}$ and $200 \mathrm{kPa}$. CRR was defined at a double axial strain of $5 \%$ in 15 cycles of uniform load application. The available data showed that the CRR-normalized cone penetration resistance $\left(\mathrm{q}_{\mathrm{c} 1 \mathrm{~N}}\right)$ correlation developed from laboratory tests on two sand specimens consistently fell below the correlations proposed by Stark and Olson (1995). Kokusho et al. (2005) carried out miniature cone penetration tests and subsequent cyclic loading tests on the same triaxial test specimen. Mini-cone was penetrated into the specimen at a constant speed. The CRR was defined at a double axial strain of 5\% in 20 cycles of uniform loading. The CRR- $\mathrm{q}_{\mathrm{c} 1 \mathrm{~N}}$ relationship was established, 
and the available data showed that the points were concentrated in a narrow area, which may be represented by a single straight line. In fact, they found a single correlation between the CRR and the cone penetration resistance, despite large differences in relative density or fines content.

Based on the discussions in the 1996 NCEER and 1998 NCEER/NSF workshops (2001), the curve prepared by Robertson and Wride (1998) has accounted for the recently available data used in the final accepted liquefaction screening chart created from the field liquefaction observations and CPT tests (Fig. 1). This figure shows $\mathrm{q}_{\mathrm{c} 1 \mathrm{~N}}$ versus cyclic stress ratio (CSR $=\tau_{\mathrm{ave}} / \sigma_{\mathrm{vo}}{ }^{\prime}$ ) induced by the earthquakes and corrected for 7.5 magnitude $\left(\mathrm{M}_{\mathrm{w}}\right)$, at many sites where the liquefaction problem during earthquakes may or may not have been observed. The number of cycles $(\mathrm{N})$ corresponding to 7.5 magnitude earthquake was suggested to be around a value of 15 (Finnie and Randolph, 1994; Green and Terri, 2005). This figure illustrates three CRR curves corresponding to the non-/low plastic fines content of $\mathrm{FC} \leq 5 \%, \mathrm{FC}=15 \%$, and $\mathrm{FC}=35 \%$. The clean sand based CRR curve ( $\mathrm{FC} \leq 5 \%$ ) drawn between the liquefied, and the non-liquefied sites in the CPT-based liquefaction screening chart is adjusted by correcting the CPT tip resistance with the fines content correction factor (Robertson and Wride, 1998). The demarcation lines are used to determine the cyclic resistance ratio $(\mathrm{CRR})_{7.5}$, with a given value of $\mathrm{q}_{\mathrm{c} 1 \mathrm{~N}}$. In order to account for the differences in the number of cycles, frequency content etc., (CRR) 7.5 needs to be corrected by the magnitude scaling factor (Youd et al., 2001). This figure displays that the relationship between liquefaction resistance and cone penetration resistance is highly dependent on silt content. However, it is not clear whether the existence of fines increases liquefaction resistance or lowers cone penetration resistance.

In this study, field-based data are used (1) to gain detailed insight regarding the effects of non-/low plastic fines on normalized cone penetration resistance, and (2) to understand the effects of fines on liquefaction resistance at the current accepted CPT-based liquefaction assessment method proposed by Robertson and Wride (1998). Four in-situ tests (piezocone penetration test, pore pressure dissipation test, direct push permeability test, and standard penetration test) were conducted side by side at 20 different sites located on the northern coast of the Izmir Gulf in Turkey. The disturbed soil samples were retrieved from the SPT spoon for comprehensive laboratory testing. In the first part of this paper, field-and laboratory-test results, used to find the drainage effects of fines or consolidation characteristics of soils on cone penetration resistance at different relative densities are discussed. The second part focuses on the change of the liquefaction

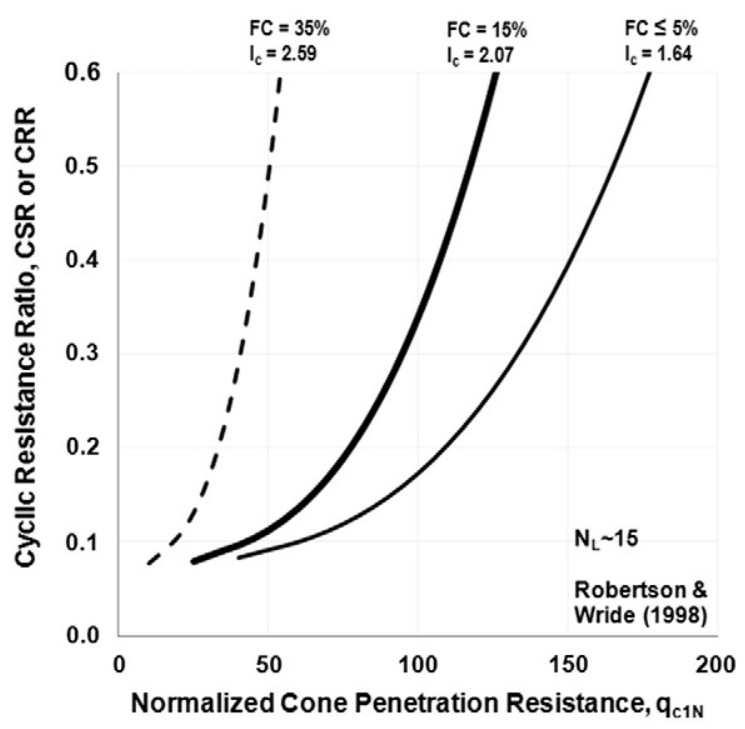

Fig. 1. CPT-based criteria for liquefaction resistance of clean sands and sands with fines (Robertson and Wride, 1998). resistance of soils with relative density at different fines content. The liquefaction resistance of the soils is directly reinterpreted from the CPTbased liquefaction assessment method (Robertson and Wride, 1998). The interpreted trend of the CPT criteria does not provide consistent effects of non-plastic fines on liquefaction resistance with available laboratory-based correlations obtained by several previous researchers (e.g. Zlatovic and Ishihara, 1997; Polito and Martin, 2001; Chien et al., 2002; Thevanayagam and Martin, 2002; Kokusho, 2007; Cubrinovski et al., 2010).

\section{Field testing program}

A set of four high-quality field tests were performed at 20 different locations on the Northern coast of the Izmir Gulf: (1) piezocone penetration test (CPTu), (2) pore pressure dissipation test (PPDT), (3) direct push permeability test (DPPT), and (4) standard penetration test (SPT). Fig. 2 displays a view of these test locations. As shown in Fig. 3a the set of tests listed above were conducted in proximity at each location, to minimize the differences in stratigraphy. This close spacing between the tests had the potential to influence the test results, were there to be any interference from previous soundings. For instance, the mud-rotary method used for drilling the SPT borehole could have affected the other three test results. In order to eliminate this effect, the sequence of the field tests was determined to be CPTu, PPDT, DPPT, and SPT.

The total sounding depth for each test was about $15 \mathrm{~m}$. The test locations were carefully selected from the knowledge of the local geology preserved in the RADIUS project report (1999) and by considering the following criteria: (1) sandy soils must mostly contain 0-30\% non-/low plastic fines content, given that fines content over $30 \%$ by weight and/or high plasticity of fines is known to affect liquefaction resistance of fines containing sands. (2) The groundwater level should be high enough to ensure that the data would be obtained under fully saturated conditions. In the study area, the soil consisted of mainly quaternary sediments. Quaternary unit consists of slope wash and alluvial soils, which are alluvial fan deposits with deltaic features. These sediments are mainly saturated and are formed by sedimentation of the alluvial deposits transported by the Gediz River. The above given tests and test area offered a test bed opportunity to examine the influence of fines on the cone penetration resistance and liquefaction resistance of soils. The field- and laboratorytest data were reported and analyzed at recent research projects TUBITAK-110M602 (2013) and EU-Marie Curie IRG-248218 (2014).

\subsection{Piezocone penetration test - cone penetration resistance and pore pressure}

The piezocone penetration testing (CPTu) device used in this study was manufactured by Geotech Inc., Sweden. These tests were conducted by using the Geotech CPT classic probe, which has $60^{\circ}$ tip angle and $35.7 \mathrm{~mm}$ diameter ( $10 \mathrm{~cm}^{2}$ tip area). As shown in Fig. $3 \mathrm{~b}$, the independent measured parameters are cone penetration resistance $\mathrm{q}_{\mathrm{c}}$, friction resistance $\mathrm{f}_{\mathrm{s}}$, and pore water pressures above the cone face (referred to as the $\mathrm{u}_{2}$ position) for each $1 \mathrm{~cm}$ of penetration. The measured data were digitized inside the probe and then transferred acoustically (without a cable down the hole) to the data acquisition system on the ground surface. This procedure was faster than using cables and provided a continuous profile for all test results. In order to obtain a satisfactory pore pressure response during a piezocone test, complete saturation of the piezocone was essential. Hence, before starting each CPTu sounding, the porous element was saturated with glycerin (Campanella et al., 1986). At each location, CPTu soundings were performed with a constant penetration speed of $20 \mathrm{~mm} / \mathrm{s}$ (ASTM D3441). The measured cone penetration resistance and friction resistance values were normalized based on the equations stated below (Youd et al., 2001):

$\mathrm{q}_{\mathrm{c} 1 \mathrm{~N}}=\mathrm{C}_{\mathrm{q}}\left(\frac{\mathrm{q}_{\mathrm{c}}}{\mathrm{P}_{\mathrm{a}}}\right)$ 
$\mathrm{C}_{\mathrm{q}}=\left(\frac{\mathrm{P}_{\mathrm{a}}}{\sigma_{\mathrm{vo}}{ }^{\prime}}\right)^{\mathrm{n}}$

where $\mathrm{P}_{\mathrm{a}}=$ atmospheric pressure; $\sigma_{\mathrm{vo}}{ }^{\prime}=$ effective vertical stress in the same units as $\mathrm{P}_{\mathrm{a}}$; and $\mathrm{n}=0.784-0.521 \mathrm{D}_{\mathrm{r}}$ (Boulanger, 2003), which is the stress exponent.

The relative density values were estimated from the measured cone penetration resistance by using the empirical relationship given by Lunne et al. (1997).

$\mathrm{D}_{\mathrm{r}}=-98+66^{*} \log _{10}\left(\frac{\mathrm{q}_{\mathrm{c}}}{\sqrt{\sigma_{\mathrm{vo}}}}\right)$

where $D_{\mathrm{r}}$ is the relative density in percentage and $\sigma_{\mathrm{vo}}$ ' is the effective vertical stress in the same units as, $\mathrm{q}_{\mathrm{c}}$.

To exemplify, Fig. $4 \mathrm{a}-\mathrm{b}$ displays the $\mathrm{q}_{\mathrm{c}}$ and excess pore pressure $\Delta \mathrm{u}_{2}$ $\left(=\mathrm{u}_{2}-\mathrm{u}_{0}\right)$ profiles obtained from location $\mathrm{L} 16$ with a constant penetration velocity of $20 \mathrm{~mm} / \mathrm{s}$. The depth of the ground water table at the study area was observed by two techniques: (1) observation wells and (2) penetration-induced pore water pressures measured by the $\mathrm{CPTu}$. The groundwater level of $1.2 \mathrm{~m}$ denoted on the log detected from the observation wells was consistent with the penetrationinduced pore water pressures measured by the CPTu at site L16. In general, the water level at the field test area varied from $1 \mathrm{~m}$ to $3 \mathrm{~m}$ below the ground surface. Fig. 4c shows the soil stratigraphy accomplished by the charts that linked cone parameters to soil type (Robertson, 1990). It is noticed that, during the examination of the depth-pore water pressure diagram, the $\Delta \mathrm{u}_{2}$ values exhibited significant negative excess pore water pressures at clean sands compared to silty sands located from $2.5 \mathrm{~m}$ to $11 \mathrm{~m}$ and from $14.5 \mathrm{~m}$ to $16 \mathrm{~m}$ below the surface. This suggests that the soils throughout these depths were particularly dense sand.

\subsection{Pore pressure dissipation test - flow and pore water dissipation}

Following the CPTu tests, pore pressure dissipation tests (PPDT) were conducted at depth intervals of almost $1.0 \mathrm{~m}$ at $2.6 \mathrm{~m}$ apart from the corresponding CPTu soundings. PPDT tests were performed based on ASTM D5778-12. Fig. 5 displays the dissipation curves at location L16. These curves show the variation of excess pore pressure $\Delta \mathrm{u}_{2}$ normalized by effective stress $\left(\sigma_{\mathrm{vo}}{ }^{\prime}\right)$ with time at different depths. The monotonically decreasing pore water pressure dissipation curves were obtained at depths of $11.5 \mathrm{~m}, 12.3 \mathrm{~m}$, and $13.8 \mathrm{~m}$. When the dissipation was monotonic, the recorded times for $50 \%$ pore pressure dissipation $\left(t_{50}\right)$ were assessed by theoretical solutions presented by Teh and Houlsby (1991). The measured $t_{50}$ was used in conjunction with the empirical correlation proposed by Parez and Fauriel (1988) to deduce the horizontal hydraulic conductivity $\left(\mathrm{k}_{\mathrm{h}}\right)$. However, from $4 \mathrm{~m}$ to $11 \mathrm{~m}$ below the surface, essentially partially drained response was observed at the time of penetration and the measured pore water pressures were almost hydrostatic. In clean sands and silty sands that are pervious, the recorded times for $50 \%$ pore pressure dissipation were less than $60 \mathrm{~s}$, with some less than $1 \mathrm{~s}$. It was difficult to record the dissipation time accurately at these depths. Hence, except for the depths of $11.5 \mathrm{~m}, 12.3 \mathrm{~m}$, and $13.8 \mathrm{~m}$, the abovementioned dissipation curves did not provide a reliable means of estimating the coefficient of consolidation. The theoretical studies of Silva et al. (2006) and experimental studies of Schneider et al. (2007) illustrate that the evaluation of the coefficient of consolidation from the dissipation tests in soils that exhibit partial consolidation during installation may underestimate the hydraulic conductivity and coefficient of consolidation.

In conclusion, dissipation tests performed at depths where penetration is partially drained cannot provide a reliable means of estimating the hydraulic conductivity. Therefore, in this study, measurements from dissipation tests were used to find the hydraulic conductivity of the clayey silts and clays. As an example, Fig. 4d depicts the measured depth-hydraulic conductivity illustration at one location, L16. The

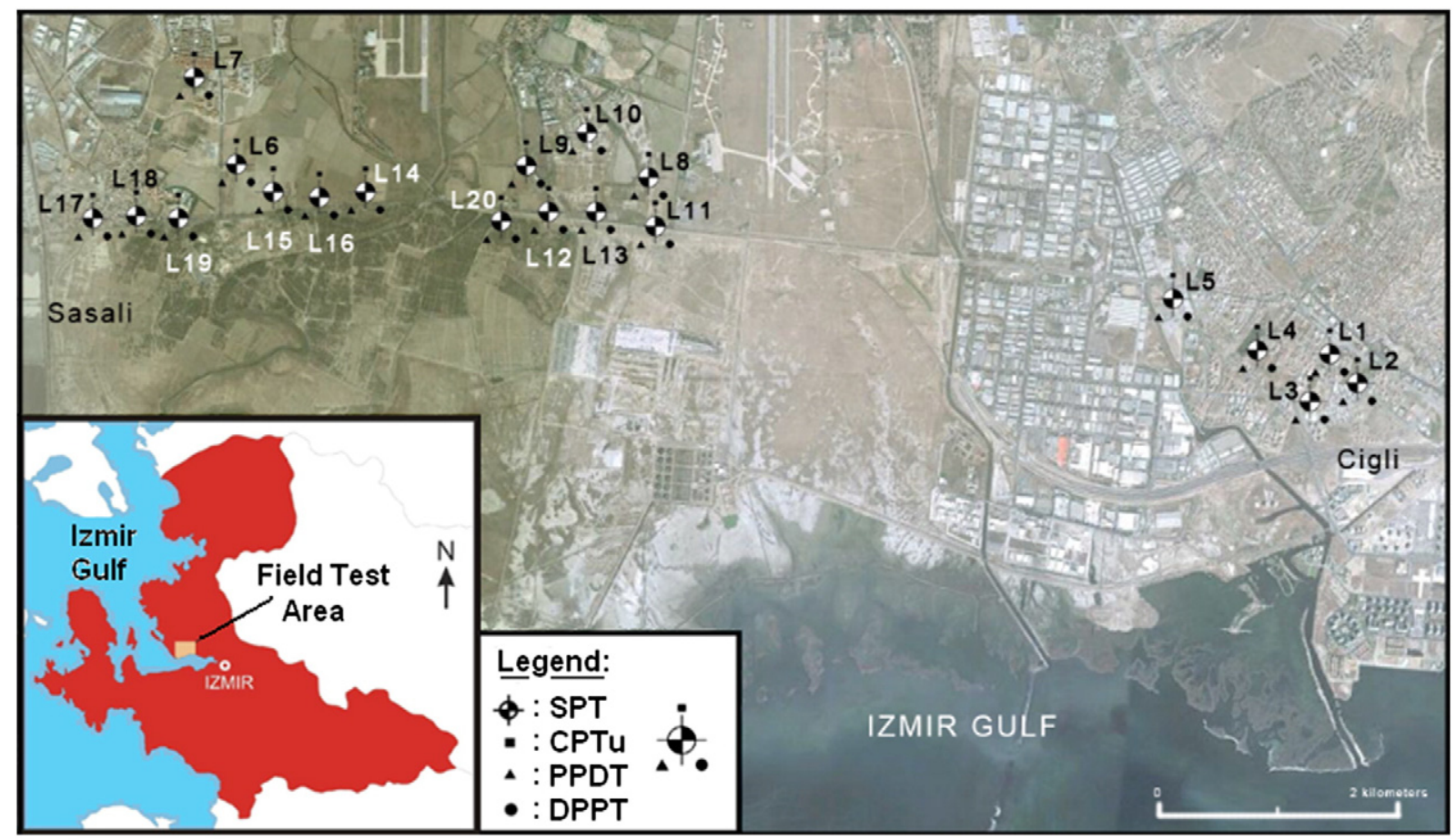

Note: SPT=Standard Penetration Test, CPTu= Piezocone Penetration Test, DPPT= Direct Push Permeability Test, $\mathrm{PPDT}=$ Pore Pressure Dissipation Test

Fig. 2. Area view of test profile locations on the northern coast of Izmir Gulf in Turkey. 


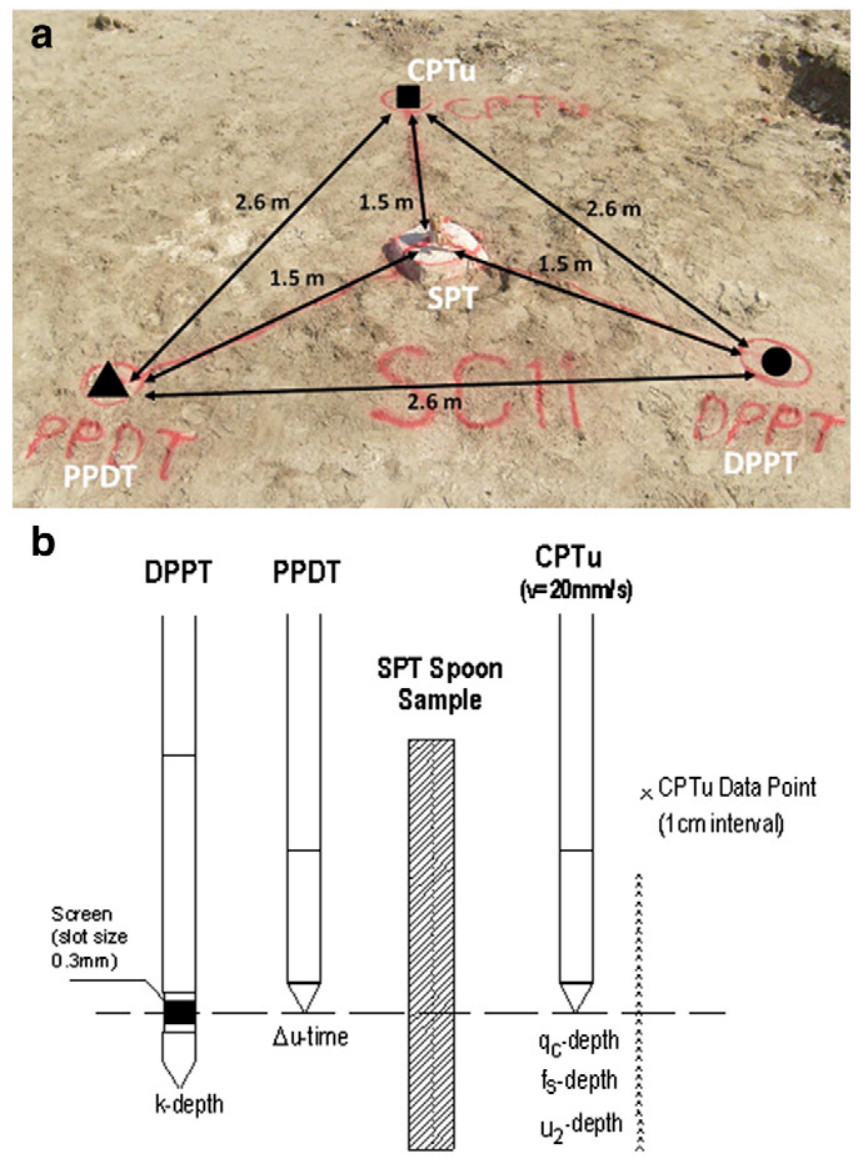

Note: $\mathrm{k}$-depth = nydraulic conductivity versus depth, $\mathrm{q}_{\mathrm{c}}$-depth $=$ cone penetration resistance versus depth, $\mathrm{f}_{\mathrm{s}}$-depth $=$ sleeve friction versus depth, $\mathrm{u}_{2}$-depth = pore pressure versus depth, $\Delta$ u-time $=$ excess pore water pressure versus time

Fig. 3. a. Plan view of in-situ test holes, b. an illustration of a SPT spoon sample and hydraulic conductivity data points with corresponding depths of piezocone penetration test.

diamonds shown in the figure display the hydraulic conductivity obtained from the dissipation tests. For the levels where we observed the sands and silty sands, the other testing method, which is the direct push permeability test, is likely to provide better results.

\subsection{Direct push permeability test - hydraulic conductivity}

Depth detached data of the soil hydraulic conductivity were obtained in the field by direct push permeability tests (DPPT) at depth intervals of $1.0 \mathrm{~m}$ (depths where pore pressure dissipation tests were performed). As shown in Fig. 3a, these tests were conducted $2.6 \mathrm{~m}$ apart from the corresponding pore pressure dissipation and CPTu tests. The direct push permeability tool is a combination of a specially fabricated cylinder with valve attachment points for water and compressed gas inlets/outlets, and a screened probe tip fabricated with a $60^{\circ}$ tapered and $35.7 \mathrm{~mm}$ diameter cone (Lee et al., 2008). According to the design specifications of Lee et al. (2008), this tool is specially fabricated to attach directly to the available CPTu rods. The permeability test involved the following steps (Lee et al., 2008): (1) rapidly pressurizing the water column in the aboveground tank via compressed nitrogen gas and (2) measuring the flow speed of the water manually as a volume discharged over a measured time under constant pressure. Water discharge into the soil was through the $45 \mathrm{~mm}$ length perforated screen, with a slot size of $0.3 \mathrm{~mm}$ (Fig. 3b). Hydraulic conductivity was recovered from the applied excess head, $\Delta \mathrm{h}$, and measured volumetric flow, Q through the spherical form of Darcy's law (Lee et al., 2008):

$\mathrm{k}_{\mathrm{h}}=\frac{\mathrm{Q}}{4 \pi \Delta \mathrm{ha}_{\mathrm{s}}}$

where $a_{s}$ is the effective radius of the spherical injection zone, which is calculated as $1.44 \mathrm{~cm}$ in this study.

Based on the test results, it is concluded that it is not possible to accurately obtain back-calculated hydraulic conductivity results from Darcy's law in clayey layers. It is believed that these impermeable layers are strongly influenced by the permeable neighboring zones. Hence, the permeability data collected at depths where clay soils were identified by the CPTu results (Robertson, 1990) were disregarded within this testing method. Only the hydraulic conductivity values of clean sand and sandy silt layers were obtained within this measurement technique. Fig. $4 \mathrm{~d}$ shows the measured depthhydraulic conductivity illustration at one location, L16. The circles shown in the figure indicate the hydraulic conductivity measured from the direct push permeability tests.

\subsection{Standard penetration test - sample collection}

Next, the disturbed soil samples were retrieved from the SPT spoon at approximately $1.5 \mathrm{~m}$ intervals for comprehensive laboratory testing. The laboratory testing program for disturbed soil samples included basic soil characterization tests such as the sieve analysis test (ASTM D6913-04), hydrometer test (ASTM D422-63), and plastic limit tests (ASTM D4318-10). Close to $45 \mathrm{~cm}$ long soil samples were procured from the SPT spoon. The first $15 \mathrm{~cm}$ interval of the split spoon sample was typically disregarded because of soil disturbance. The usable portion of the sample was taken from the bottom $2 / 3$ of the split spoon (about $15-45 \mathrm{~cm}$ ). CPTu soundings used for this paper provided data at intervals of $1 \mathrm{~cm}$, so approximately 30 data points were obtained for a single SPT data point.

Fig. 3b shows the illustrations of the SPT spoon sample where the permeability data and the corresponding CPTu test data were obtained. A $30 \mathrm{~cm}$ long soil sample from the SPT spoon was mixed and then tested for classification in the laboratory. In order to ensure the desired side by side comparison, the soil stratigraphy was first accomplished by the charts that linked cone parameters to soil type (Robertson, 1990). Second, the Unified Soil Classification System (USCS) based on grainsize distribution and soil plasticity was used. In total, 64 samples from 20 boreholes were classified in the laboratory, and their corresponding soil types obtained from the CPTu were compared. Fig. 4c illustrates the comparison of soil classification based on USCS and interpretation from the CPTu. It depicts a reasonable agreement between the USCS-based classification and CPTu-based soil type. The comparison of the findings at any of the test sites shows that, at the same depth, the soil type does not change horizontally in about $3 \mathrm{~m}$.

\section{Effect of fines and relative density on the coefficient of consolidation}

Based on the studies of Thevanayagam and Ecemis (2008), fines content affects the permeability, compressibility, and coefficient of consolidation $\left(c_{h}\right)$ of silty sands and, therefore, influences the excess pore water pressure and the cone penetration resistance that occurs around the CPT probe. As drainage effects of fines is one of the factors affecting the measured excess pore pressure and the cone penetration resistance (Thevanayagam and Ecemis, 2008), the effects of fines and relative density $\left(D_{r}\right)$ on the coefficient of consolidation of the sands with fines must be substantiated.

In this study, the measurements from direct push permeability tests and dissipation tests were used to find the hydraulic 




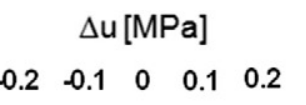

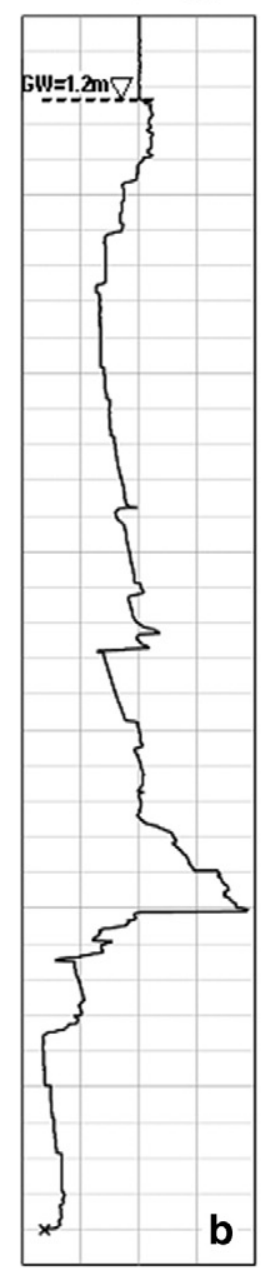



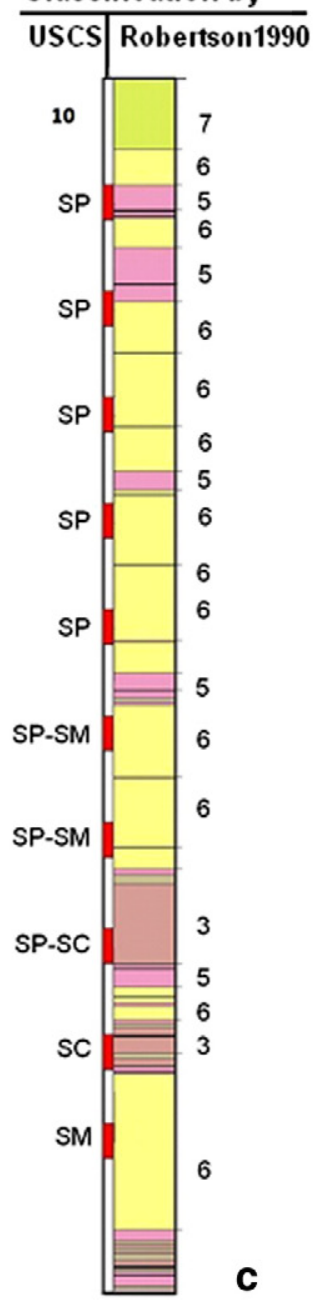

$\mathrm{k}[\mathrm{m} / \mathrm{sec}]$

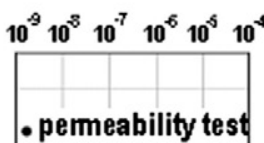

$\Delta$ dissipation test

\begin{tabular}{|ll||cl|}
\hline Group & & Gorup & \\
Symbol & USCS- based soil type & No & Robertson 1990 soil type \\
SP & Poorly graded sand & 3 & Clay- clay to silty clay \\
SM & Silty sand & 4 & Silt mixture; clayey silt to silty clay \\
SC & Clayey Sand & 5 & Sand mixture; silty sand to sandy silt \\
SP-SM & Sand, silty sand mixture & 6 & Sand; clean sand to silty sand \\
SP-SC & Sand, clayey sand mixture & 7 & Gravelly sand to sand \\
\hline
\end{tabular}

Fig. 4. Example of collected and obtained data at one location, L16. a. Measured cone penetration resistance, b. excess pore water pressure, c. comparison of soil classification based on USCS and interpretation from CPTu, and d. recorded hydraulic conductivity versus depth from dissipation and direct push permeability tests.

conductivity at each depth by using the equations given by Lee et al. (2008) and Parez and Fauriel (1988). The coefficient of consolidation is influenced by a number of factors such as the effects of the penetration process, stress level, void ratio, stress history, and anisotropy. Therefore, an appropriate method is needed to determine the coefficient of the consolidation of the soil. In this paper, the coefficient of consolidation of soils throughout the depths was determined by using the equation given below:

$c_{h}=\frac{k_{h}}{m_{v} \gamma_{w}}$ where $\gamma_{w}$ is the unit weight of water, and $m_{v}$ is the compressibility of the soil estimated from the CPTu tests based on the correlation proposed by Robertson (2009):

$\mathrm{m}_{\mathrm{v}}=\frac{1}{\alpha_{\mathrm{M}}\left(\mathrm{q}_{\mathrm{t}}-\sigma_{\mathrm{vo}}\right)}$

If $\mathrm{I}_{\mathrm{C}}>2.2$ and $\mathrm{q}_{\mathrm{c} 1 \mathrm{~N}}<14$, use $\alpha_{\mathrm{M}}=\mathrm{q}_{\mathrm{c} 1 \mathrm{~N}}$. If $\mathrm{I}_{\mathrm{c}}>2.2$ and $\mathrm{q}_{\mathrm{c} 1 \mathrm{~N}}>14$, use $\alpha_{\mathrm{M}}=14$. If $\mathrm{I}_{\mathrm{c}}<2.2$, use $\alpha_{\mathrm{M}}=0.03\left[10^{\left(0.55 \mathrm{I}_{\mathrm{c}}+1.68\right)}\right]$. Where $\sigma_{\mathrm{vo}}=$ in-situ total vertical stress, $\mathrm{q}_{\mathrm{t}}=$ corrected total cone resistance, 


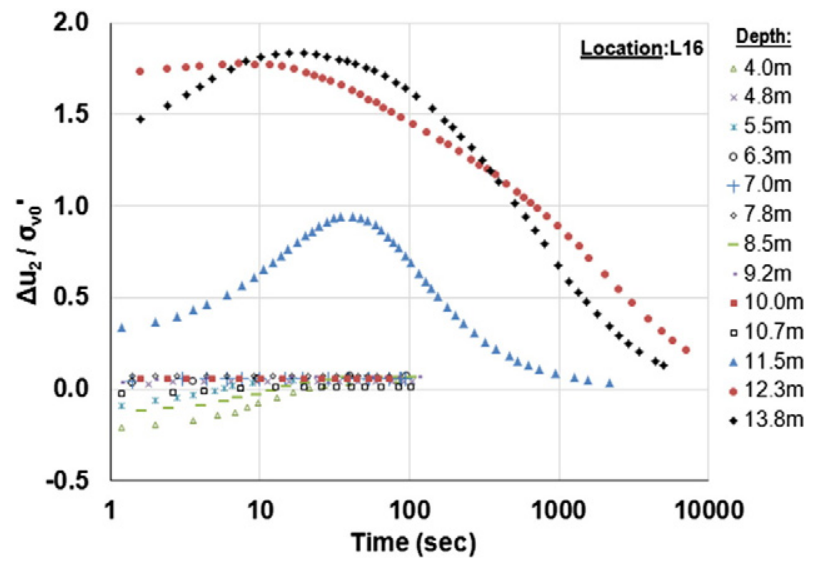

Fig. 5. The dissipation test results at location L16.

and $\mathrm{I}_{\mathrm{c}}=\left[\left(3.47-\log _{10} \mathrm{q}_{\mathrm{c} 1 \mathrm{~N}}\right)^{2}+\left(\log _{10} \mathrm{~F}+1.22\right)^{2}\right]^{0.5}$ is the soil behavior type index modified by Robertson and Wride (1998).

The measured sleeve friction $\left(\mathrm{f}_{\mathrm{s}}\right)$ values were normalized based on the equations stated below (Youd et al., 2001):

$\mathrm{F}=\frac{\mathrm{f}_{\mathrm{s}}}{\mathrm{q}_{\mathrm{c}}-\sigma_{\mathrm{v}}}$.

Fig. 6a-d illustrates the variation of the coefficient of consolidation, which is obtained from the direct push permeability tests, with fines content for four individual ranges of relative densities. In each figure, the corresponding upper and lower limit values of $D_{r}$ are given with different dotted lines. The average relative densities of $95 \%, 85 \%, 78 \%$, and $48 \%$ are represented by the solid lines. At the same relative density, the coefficient of consolidation decreases steadily with an increase in fines content up to $30 \%$. An increase in fines content significantly reduces the hydraulic conductivity and constrained modulus $(\mathrm{M}=$ $1 / \mathrm{m}_{\mathrm{v}}$ ), which decreases the coefficient of consolidation. It is apparent that there is a major difference in the coefficient of consolidation between clean sands and sands with fines, even if compared at the same relative density. In order to compare the effect of different relative densities to the relationship between the coefficient of consolidation and fines content, the variation of $c_{h}$ with FC for average $D_{r}$ obtained from the abovementioned figures was plotted together in Fig. 7. With an increase in fines content, the linear declinations of the coefficient of



Fig. 6. The change of the coefficient of consolidation with fines content (FC $\leq 30 \%$ ) at different relative density ranges (a) $D_{r} \geq 90 \%$, (b) $90 \%>D_{r} \geq 80 \%$, (c) $80 \%>D_{r} \geq 65 \%$, (d) $65 \%>D_{\mathrm{r}} \geq 30 \%$

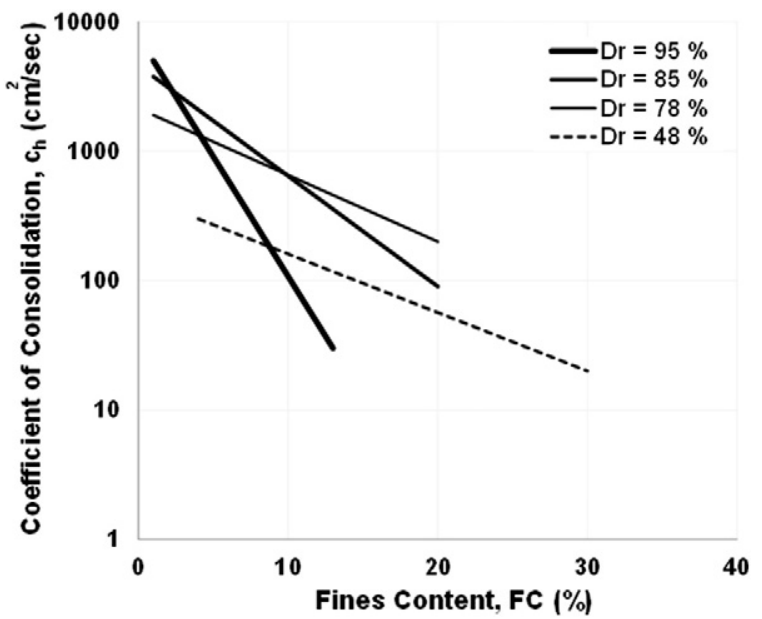

Fig. 7. Summary of the effects of fines content on the coefficient of consolidation at different relative densities.

consolidation for stiff/dense soils are determined to be greater than those in the medium dense and loose soils. The above combined observations indicate that both the fines content and the relative density affect the coefficient of consolidation of the soils. Hence, in this study, the coefficient of consolidation is used as the main indicator to find the drainage effects of fines on the cone penetration resistance.

\section{Effect of coefficient of consolidation on cone penetration resistance}

In order to scrutinize the effect of fines on liquefaction resistance based on the cone penetration test, one must understand the effects of fines on cone penetration resistance. The above manipulations enable us to express the effect of fines on cone penetration resistance in terms of the coefficient of consolidation.

It has recently been suggested that (Finnie and Randolph, 1994; House et al., 2001; Randolph and Hope, 2004; Chung et al., 2006; Kim et al., 2008; Thevanayagam and Ecemis, 2008) the measured cone penetration resistance and excess pore water pressure during penetration of the cone in soils depend on the coefficient of consolidation $\left(c_{h}\right)$, the rate of penetration (v), and the diameter of the cone (d). Finnie and Randolph (1994) proposed a non-dimensional parameter (V) as a function of $\mathrm{v}, \mathrm{d}$, and $c_{\mathrm{h}}$. This normalized penetration rate can be expressed as:

$\mathrm{V}=\frac{\mathrm{vd}}{\mathrm{c}_{\mathrm{h}}}$

Fig. 8a-f illustrates the variation of measured normalized cone penetration resistance values with log normalized penetration rate for six distinct ranges of relative density. In this study, the normalized penetration rate was changed only due to the change in the coefficient of consolidation of the soil layers. The circles shown in the figure indicate the coefficient of consolidation obtained from the direct push permeability tests. The diamonds presented in the figure show the coefficient of consolidation obtained from the dissipation tests. In each figure, while the corresponding upper and lower limit values of $D_{r}$ are displayed with different dotted lines, the average relative densities (95\%, 85\%, 78\%, 55\%, $38 \%$, and $15 \%$ ) are represented by the solid lines. For stiff/dense soils, where the relative density is more than about $80 \%$, the change of normalized penetration rate was investigated from about $10^{-3}$ to 1 . For medium dense soils, where the relative density ranges from $80 \%$ to $45 \%$, the change of normalized penetration rate was investigated from about $10^{-3}$ to $10^{3}$. For loose soils, where the relative density was smaller than $45 \%$, the change of normalized penetration rate was investigated from about $5 \times 10^{-3}$ to $10^{4}$. In order to compare the results, the variation of $\mathrm{q}_{\mathrm{c} 1 \mathrm{~N}}$ 


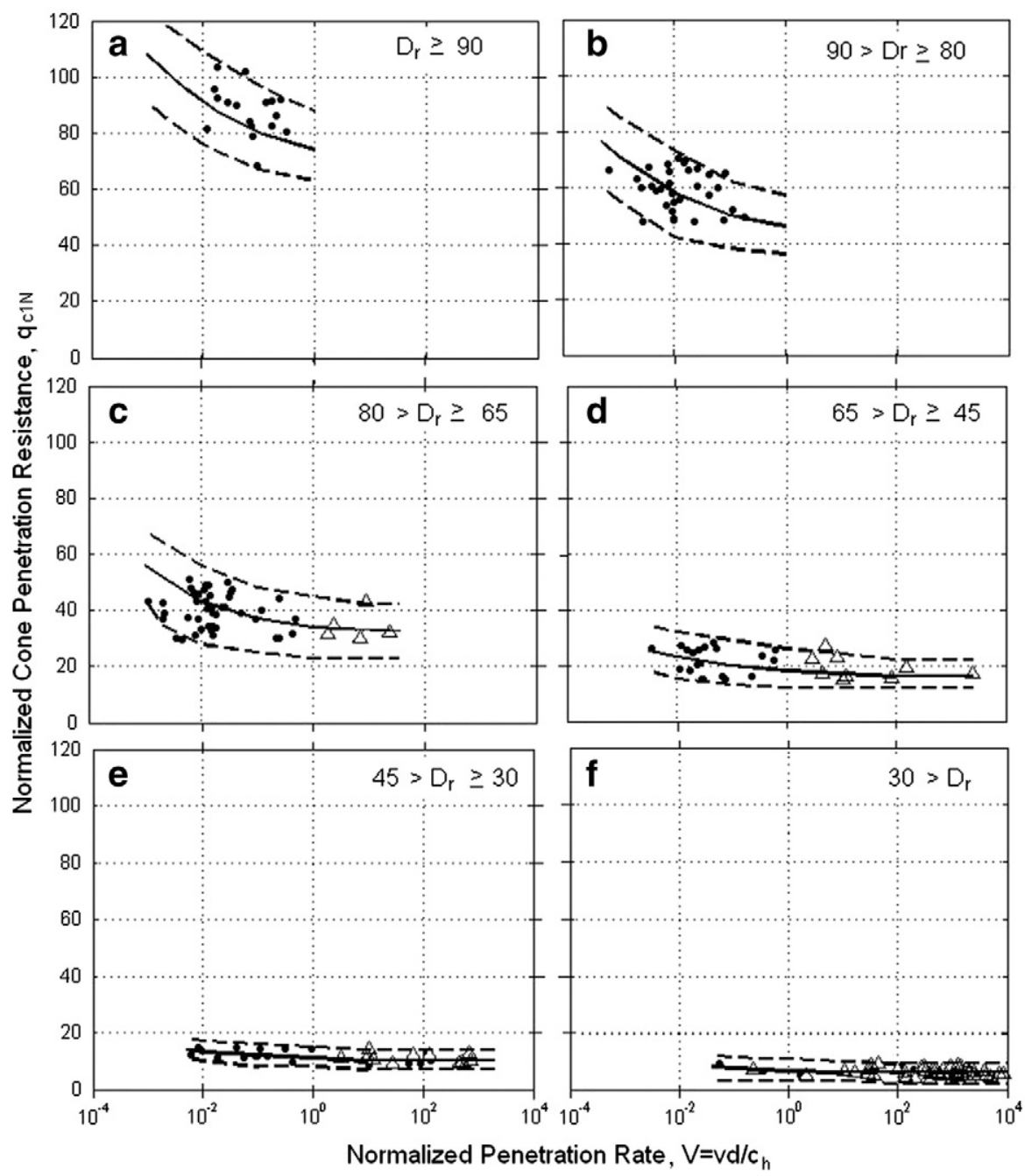

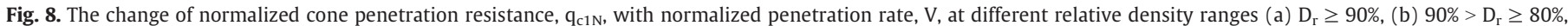
(c) $80 \%>D_{r} \geq 65 \%$, (d) $65 \%>D_{r} \geq 45 \%$, and (e) $45 \%>D_{r} \geq 30 \%$, (f) $D_{r}<30 \%$.

with normalized penetration rate for different average relative densities obtained from the abovementioned figures is also plotted together in Fig. 9.

For stiff/dense to medium dense soil, from a normalized penetration rate of $10^{-3}$ to 10 , the normalized cone resistance decreased significantly with an increase in the log of normalized penetration rate. This is attributed to the inclusion of fines that cause partially drained conditions (slow rate of dissipation of excess pore pressures) during penetration in finegrained soils leading to a decrease in cone resistance compared to clean sand. Thevanayagam and Ecemis (2008) also showed that, low coefficient of consolidation (high normalized penetration rate) values can cause lower effective stress near the penetration tip of a cone in sands with fines than in clean sand at the same contact density. For stiff/dense to medium dense soils, above normalized penetration rate of 10 there was not much alteration observed in CPT penetration resistance with an increase in $\mathrm{V}$. This shows that the transition value of normalized penetration rate from partially drained to undrained response was determined as 10 . However, for loose soils the normalized cone resistance was not significantly changed with an increase in normalized penetration rate (decrease in coefficient of consolidation) from partially drained to undrained conditions.

It is apparent that both normalized penetration rate and relative density of the dense and medium dense soils showed a significant influence on the measured CPT penetration resistance around the probe. On the other hand, for loose soils only the relative density indicated a significant influence on the measured CPT penetration resistance around the probe.

These proposed transition values of normalized penetration rate from partially drained to undrained conditions align closely with the related research conducted by Finnie and Randolph (1994), House et al. (2001), Randolph and Hope (2004), Chung et al. (2006), Kim et al. (2008), and Ecemis (2008). The results of tests conducted on circular foundations reported by Finnie and Randolph (1994) suggested the undrained limit for $\mathrm{V}$ to be around 30. A cylindrical T-bar penetrometer test analysis reported by House et al. (2001) suggested the undrained limit for V to be around 10. Similarly, Randolph and Hope (2004) observed that undrained penetration occurs at $\mathrm{V}$ of approximately 30 to 100. According to Chung et al. (2006) and Kim et al. (2008) the transition from fully undrained to partially drained conditions was approximately around 10. In the same line, based on the recent numerical simulations by Ecemis (2008), the undrained limit for $\mathrm{V}$ was in the range of about 5 to 10 .

\section{Effect of fines and relative density on cone penetration resistance}

The above correlations show that the primary quality of the penetration resistance - relative density correlation is through the use of the coefficient of consolidation. Hence, both the coefficient of consolidation values obtained for each $D_{r}$ and FC from Fig. 7 and normalized cone penetration resistance values obtained for each $D_{r}$ and $V\left(=v d / c_{h}\right)$ 


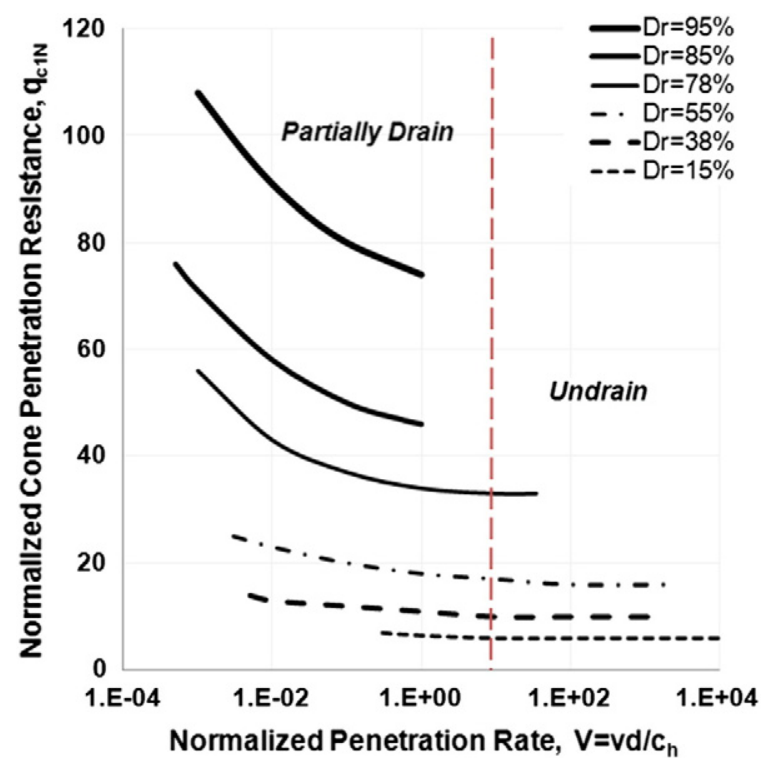

Fig. 9. Effects of normalized penetration rate and relative density on normalized cone penetration resistance.

from Fig. 9 have been used to examine the effects of $F C$ and $D_{r}$ on normalized cone penetration resistance, $\mathrm{q}_{\mathrm{c} 1 \mathrm{~N}}=f\left(\mathrm{FC}, \mathrm{D}_{\mathrm{r}}\right)$.

Fig. 10 illustrates the effects of fines on the relationship between normalized penetration resistance and relative density. A correlation between $\mathrm{q}_{\mathrm{c} 1 \mathrm{~N}}$ and $\mathrm{D}_{\mathrm{r}}$ is proposed for seven different fines contents. The contours (solid lines) shown in the figure are for fines contents $0 \%$ to $30 \%$. This figure illustrates that the fines content significantly affects the cone penetration resistance. At a given relative density, the penetration resistance significantly decreases with an increase in fines content. However, in high percent of silt, the cone tip resistance decreases more gently compared with low percent of silt.

Below 40\% relative density (loose soil) CPT resistance of sands and silty sands was not affected by the change in relative density. This can be also observed from Fig. 9. A change in relative density of clean sand from $40 \%$ to $80 \%$ (medium dense soil) increased the CPT resistance by a factor of 5 . A change in relative density of silty sand (containing $30 \%$ fines) from $40 \%$ to $80 \%$ increased the CPT resistance by a factor of 3 . A



Fig. 10. The relationship between normalized cone penetration resistance and relative density of clean sands and sands for different fines contents from $0 \%$ to $30 \%$. change in relative density of clean sand above $80 \%$ (dense soil) increased the CPT resistance by a factor of 2.5. A change in relative density of silty sand (containing 30\% fines) above $80 \%$ increased the CPT resistance by a factor of 2 . The increase in CPT resistance of clean sand determined in this study is also compatible with the estimated increase in CPT resistance given by Idriss and Boulanger (2008).

\section{Effects of fines and relative density on liquefaction resistance}

Over the past two decades, numerous researchers have conducted laboratory studies to investigate the effects of fines on the liquefaction resistance of soils (e.g. Zlatovic and Ishihara, 1997; Polito and Martin, 2001; Chien et al., 2002; Thevanayagam and Martin, 2002; Kokusho, 2007; Cubrinovski et al., 2010). The process in these studies was to directly compare the behavior of sand mixed with a specific amount of fines (less than 30\% FC by weight) to that of the clean sand. These researchers used different density measures, such as void ratio, relative density, and equivalent contact density as references for the comparison of liquefaction resistance of clean sands and sands containing fines. In most of the studies, at a given relative density a decrease in the liquefaction resistance with an increase in the fines content has been reported (e.g. Chien et al., 2002; Kokusho, 2007; Cubrinovski et al., 2010). Although successful application of these results to the geotechnical practice requires an understanding of the phenomenon observed and its limitations, the results from these laboratory studies do provide a good basis for understanding the essential influence of fines on liquefaction resistance.

In this study, the effect of fines on liquefaction resistance is quantified at different relative densities. As shown in Fig. 11, the relationship is obtained for the liquefaction resistance representing the CPT-based criteria of Robertson and Wride (1998) in terms of relative density and fines content. This relationship illustrates the change in undrained cyclic resistance ratios (CRR) 7.5 of sands and sands with fines in terms of the relative density. (CRR) 7.5 corresponds to 7.5 magnitude earthquakes, about 15 cycles (Finnie and Randolph, 1994; Green and Terri, 2005). The contours (solid lines) shown in the figure are for seven different fines contents from $0 \%$ to $30 \%$. These curves are developed by combining the effects of fines content and relative density on CPT penetration resistance (Fig. 10) and the current field-based CPT liquefaction assessment method (Fig. 1). The CPT based liquefaction screening curves for

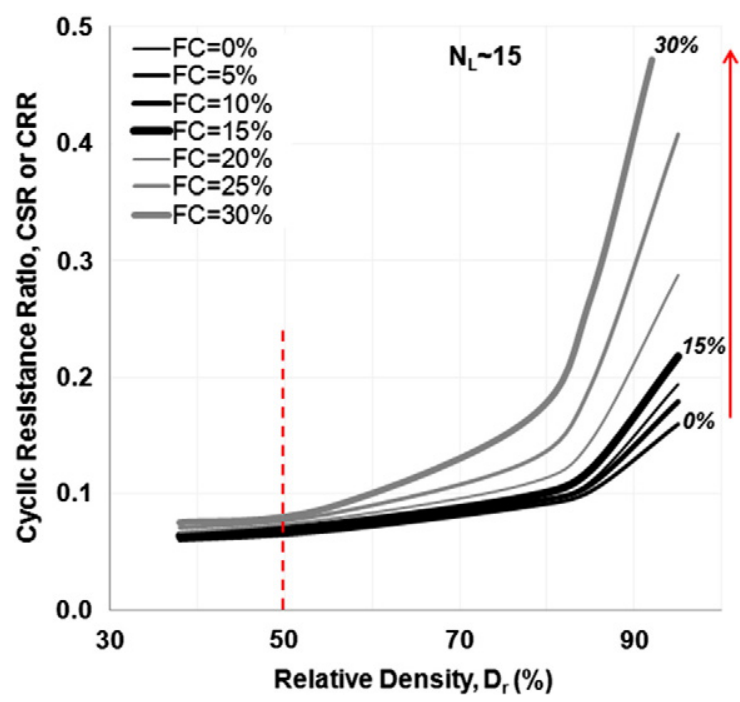

Fig. 11. The relationship between the cyclic stress ratio at about 15 cycles (estimated from the CPT based criteria for liquefaction assessment of Robertson and Wride (1998) curves) and relative density of clean sands and sands for different fines contents from $0 \%$ to $30 \%$. 
sands with fines from 0 to 35\% can also be approximated and expressed by the following equations (Robertson and Wride, 1998):

$\mathrm{CRR}_{7.5}=0.833\left[\frac{\left(\mathrm{q}_{\mathrm{c} 1 \mathrm{~N}}\right)_{\mathrm{cs}}}{1000}\right]+0.05$ for $\left(\mathrm{q}_{\mathrm{c} 1 \mathrm{~N}}\right)_{\mathrm{cs}}<50$

$\mathrm{CRR}_{7.5}=93\left[\frac{\left(\mathrm{q}_{\mathrm{c} 1 \mathrm{~N}}\right)_{\mathrm{cs}}}{1000}\right]^{3}+0.08$ for $50 \leq\left(\mathrm{q}_{\mathrm{c} 1 \mathrm{~N}}\right)_{\mathrm{cs}}<160$

where $\left(\mathrm{q}_{\mathrm{c} 1 \mathrm{~N}}\right)_{\mathrm{cs}}=\mathrm{K}_{\mathrm{c}} \mathrm{q}_{\mathrm{c} 1 \mathrm{~N}}$ and $\mathrm{K}_{\mathrm{c}}$ is the fines content correction factor.

Robertson and Wride (1998) recommended the relationship between the soil behavior type index $\left(\mathrm{I}_{\mathrm{c}}\right)$ and the fines content correction factor by the following equations:

$\mathrm{K}_{\mathrm{c}}=1.0$ for $\mathrm{I}_{\mathrm{c}} \leq 1.64$

$\mathrm{K}_{\mathrm{c}}=-0.403 \mathrm{I}_{\mathrm{c}}{ }^{4}+5.581 \mathrm{I}_{\mathrm{c}}{ }^{3}-21.63 \mathrm{I}_{\mathrm{c}}{ }^{2}+33.71 \mathrm{I}_{\mathrm{c}}-17.88$ for $\mathrm{I}_{\mathrm{c}}>1.64$.

The simplified relationship between fines content and soil behavior type index is suggested by Robertson and Fear (1995) as:

For $\mathrm{FC}=0 \% \quad \mathrm{I}_{\mathrm{c}}<1.26$.

For $0 \%<\mathrm{FC}<100 \% \quad \mathrm{I}_{\mathrm{c}}=\sqrt[3.25]{\frac{\mathrm{FC}+3.7}{1.75}}$.

For $\mathrm{FC}=100 \% \quad \mathrm{I}_{\mathrm{C}}>3.5$.

Fig. 11 clearly indicates that for the same relative density up to about $50 \%$ (loose soil), cyclic resistance of sands containing fines is similar to that of clean sand. This trend is also compatible with the studies given by Cubrinovski et al., 2010. A pronounced increase in liquefaction resistance is observed with an increase in fines content (FC) above $50 \%$ relative density. For medium dense soil, as FC increased from $0 \%$ to $15 \%$, the $(\mathrm{CRR})_{7.5}$ slightly increased by a factor of 1.1 , whereas $(\mathrm{CRR})_{7.5}$ increased by a factor of 1.7 with an increase in fines content from $15 \%$ to $30 \%$. For stiff/dense soil, as FC increased from $0 \%$ to $15 \%$, the $(C R R)_{7.5}$ slightly increased by a factor of 1.3 , whereas (CRR) 7.5 increased by a factor of 2.4 with an increase in fines content from $15 \%$ to $30 \%$.

In summary, (1) liquefaction resistance of loose silty sands is similar to that of clean sand, (2) above 50\% relative density, the increase in liquefaction resistance from $0 \%$ to $15 \%$ fines content is smaller than the increase in liquefaction resistance from $15 \%$ to $30 \%$ fines content. Clearly, the increase of CRR in the CPT based liquefaction assessment (Fig. 1) with an increase in fines content is caused by a both decrease in the cone penetration resistance and an increase in the liquefaction resistance. However, several previous researchers in the literature reported that liquefaction resistance decreases with an increase in fines content at the same relative density. This inconsistency shows that the use of the current method to estimate the liquefaction resistance from CPT data causes some uncertainty. Therefore, there will be possibly some inaccuracies in estimation of liquefaction potential of silty sand using the current CPT-based liquefaction assessment method.

\section{Conclusions}

In this study, field-based data are used (1) to find the effects of non-/low plastic fines on normalized cone penetration resistance, and (2) to evaluate the effects of non-/low plastic fines on liquefaction resistance at the current CPT-based liquefaction assessment method proposed by Robertson and Wride (1998). The findings are practicable merely for clean sands and sands containing relatively small amount of non-/low plastic fines (typically $\mathrm{FC} \leq 30 \%$ ). The following results can be summarized as follows:

1. Both relative density and fines content affect the coefficient of consolidation of the soil. In this light, first the changing trends of cone penetration resistance according to the relative density were established for different drainage effects of fines or coefficient of consolidation of soils. The coefficient of consolidation indicates a significant influence on the measured penetration resistance during insertion of the $\mathrm{CPT}$ cone into soils having different relative densities. For stiff/dense and medium dense soil, at the same relative density a decrease in normalized cone resistance was observed due to the change in drainage characteristics of fines or the coefficient of consolidation of the sands containing fines. However, for loose soils only relative density indicated a significant influence on the measured CPT penetration resistance around the probe.

2. CPT-based criteria for liquefaction assessment (Robertson and Wride, 1998) were re-interpreted and offered in a form allowing direct estimation of the influence of fines on the liquefaction resistance in terms of the relative density. This interpretation indicates that at a given relative density, the liquefaction resistance of sandy soils increases with increased fines content.

The abovementioned results show that the increase of liquefaction resistance in the CPT-based liquefaction assessment with an increase in fines content is caused by a both decrease in the cone penetration resistance and an increase in the liquefaction resistance. This finding is compared with the laboratory-based correlations obtained by several previous researchers, which is available in the literature. The discrepancy of the interpreted trend shows that the use of the current CPT based method in the evaluation of liquefaction potential of silty sand may cause some uncertainty. Therefore, there may be some errors in evaluation of liquefaction potential of silty sand using the current CPT-based liquefaction assessment method.

\section{Acknowledgments}

The financial support by the Scientific and Technological Research Council of Turkey, TUBITAK (Grant number: 110M602) and the European Union 7th framework program Marie Curie fellowship (Grant number: PIRG05-GA-2009-248218) is gratefully appreciated.

\section{References}

Boulanger, R.W., 2003. High overburden stress effects in liquefaction analyses. J. Geotech. Geoenviron. Eng. ASCE 129 (12), 1071-1082.

Bray, J., Sancio, R., 2006. Assessment of the liquefaction susceptibility of fine-grained soils. J. Geotech. Geoenviron. Eng. ASCE 132 (9), 1165-1177.

Cai, G.J., Liu, S.Y., Puppala, A.J., 2012. Liquefaction assessments using seismic piezocone penetration (SCPTU) test investigations in Tangshan region in China. Soil Dyn. Earthq Eng. 41, 141-150.

Campanella, R.G., Robertson, P.K., Gillespie, D., 1986. Seismic cone penetration test. Use of in situ Tests in Geotechnical Engineering. GSP 6ASCE, Blacksburg. VA, pp. 116-130.

Carraro, J.A.H., Bandini, P., Salgado, R., 2003. Liquefaction resistance of clean and non-plastic silty sands based on cone penetration resistance. J. Geotech. Geoenviron. Eng. ASCE 129 (11), 965-976.

Casagrande, A., 1975. Liquefaction and cyclic deformation of sands-a critical review. Proceedings of the Fifth Pan American Conference on Soil Mechanics and Foundation Engineering, Buenos Aires, Argentina.

Castro, G., 1975. Liquefaction and cyclic mobility of saturated sands. J. Geotech. Eng. Div. ASCE 101 (GT6), 551-569.

Chien, L.K., Oh, Y.N., Chang, C.H., 2002. Effects of fines content on liquefaction strength and dynamic settlement of reclaimed soil. Can. Geotech. J. 39 (1), 254-265.

Chung, S.F., Randolph, M.F., Schneider, J.A., 2006. Effect of penetration rate on penetrometer resistance in clay. J. Geotech. Geoenviron. Eng. ASCE 132 (9), 1188-1196.

Cubrinovski, M., Rees, S., Bowman, E., 2010. Effects of non-plastic fines on liquefaction resistance of sandy soils. Earthquake Engineering in Europe, Geotechnical, Geological, and Earthquake Engineering. 17, pp. 125-144

Ecemis, N., 2008. Effects of Permeability and Compressibility on Liquefaction Screening Using Cone Penetration Resistance. (Ph.D. Dissertation) Department of Civil Structura and Environmental Engineering; State University of New York at Buffalo, (282p.). 
Ecemis, N., 2013. Effects of consolidation characteristics on CPT cone resistance and liquefaction resistance in silty soils. The Scientific and Technological Research Council of Turkey-TUBITAK, Project No: 110M602, Ankara, Turkey.

Ecemis, N., 2014. Effects of permeability and compressibility on liquefaction assessment of silty soils using cone penetration resistance. European Union 7th Framework Program Marie Curie Fellowship, Grant No: PIRG05-GA-2009-248218.

Finn, W.D.L., Pickering, D.J., Bransby, P.L., 1971. Sand liquefaction in triaxial and simple shear tests. J. Soil. Mech. Found. Div. ASCE 97 (SM4), 639-659.

Finnie, I.M.S., Randolph, M.F., 1994. Punch-through and liquefaction induced failure of shallow foundations on calcareous sediments. Proc. Int. Conf. on Behavior of Offshore Structures, Boston, pp. 217-230.

Green, R.A., Terri, G.A., 2005. Number of equivalent cycles concept for liquefaction evaluations - revisited. J. Geotech. Geoenviron. Eng. ASCE 131 (4), 477-488.

House, A.R., Oliveira, J.R.M.S., Randolph, M.F., 2001. Evaluating the coefficient of consolidation using penetration tests. Int. J. Phys. Model. Geotech. 1 (3), 17-25.

Huang, A.B., Huang, Y.T., Ho, F.J., 2005. Assessment of liquefaction potential for a silty sand in Central Western Taiwan. 16th ICSMGE, pp. 2653-2657.

Idriss, I.M., Boulanger, R.W., 2008. Soil liquefaction during earthquakes. Earthquake Engineering Research Institute, (MNO-12).

Juang, C.H., Rosowsky, D.V., Tang, W.H., 1999. Reliability-based method for assessing liquefaction potential of sandy soils. J. Geotech. Geoenviron. Eng. ASCE 125 (8), 684-689.

Kim, K., Prezzi, M., Salgado, R., Lee, W., 2008. Effect of penetration rate on cone penetration resistance in saturated clayey soils. J. Geotech. Geoenviron. Eng. ASCE 134 (8), $1142-1153$.

Kokusho, T., 2007. Liquefaction strength of poorly-graded and well-graded granular soils investigated by lab. tests. Earthquake Geotechnical EngineeringSpringer, Dordrecht, pp. 159-184.

Kokusho, T. Hara, T, Murahata, K, 2005. Liquefaction strength of fines containing sands compared with cone resistance in triaxial specimens. Pre-Workshop Proc. 2nd Japan-US Workshop on Testing, Modelling, and Simulation in Geomechanics, Kyoto, Japan, pp. 280-296.

Lee, K.L., 1976. Fundamental considerations for cyclic triaxial tests on saturated sands. Proceedings International Conference on Behavior of Offshore Structures, Trondheim, Norway.

Lee, D.S., Elsworth, D., Hryciw, R., 2008. Hydraulic conductivity measurement from on-the-fly uCPT sounding and from VicCPT. J. Geotech. Geoenviron. Eng. ASCE 134 (12), 1720-1729.

Lunne, T., Robertson, P.K., Powell, J.J.M., 1997. Cone Penetration Testing in Geotechnica Practice. Blackie Academic, FF Spon/Routledge Publishers, New York, (312p).

Mayne, P.W., 2007. Cone penetration testing: state of practice. NCHRP Report Transportation Research Board, Washington, D.C.,(No. 20-05)
Parez, L., Fauriel, R., 1988. Le piezocone ameliorations apportees a la reconnaissance de sols. Rev. Fr. Géotech. 44, 13-27.

Polito, C.P., Martin II, J.R., 2001. Effects of non-plastic fines on the liquefaction resistance of sands. J. Geotech. Geoenviron. Eng. ASCE 127 (5), 408-415.

RADIUS Project, 1999. Izmir deprem senaryosu ve master plani. website: http://www. izmirbld.gov.tr/izmirdeprem/izmirrapor.htm.

Randolph, M.F., Hope, S., 2004. Effect of cone velocity on cone resistance and excess pore pressures. Proc. Int. Sym. on Eng. Practice and Performance of Soft Deposits, Osaka, pp. 147-152.

Robertson, P.K., 1990. Soil classification using the cone penetration test. Can. Geotech. J. 27 (1), 151-158.

Robertson, P.K., 2009. Interpretation of cone penetration tests - a unified approach. Can. Geotech. J. 46 (11), 1337-1355.

Robertson, P.K., Fear, C.E., 1995. Liquefaction of sands and its evaluation. First International Conference on Earthquake Geotechnical Engineering, Tokyo, Keynote Lecture.

Robertson, P.K., Wride, C.E., 1998. Evaluating cyclic liquefaction potential using the cone penetration test. Can. Geotech. J. 35 (3), 442-459.

Schneider, J.A., Lehane, B.M., Schnaid, F., 2007. Velocity effects on piezocone tests in normally and overconsolidated clays. Int. J. Phys. Model. Geotech. 7 (2), 23-34.

Seed, H.B., 1976. Evaluation of soil liquefaction effects on level ground during earthquakes. Liquefaction Problems in Geotechnical EngineeringASCE, pp. 1-105.

Shuttle, D.A., Cunning, J., 2007. Liquefaction potential of silts from CPTu. Can. Geotech. J. $44(1), 1-19$.

Silva, M.F., White, D.J., Bolton, M.D., 2006. An analytical study of the effect of penetration rate on piezocone tests in clay. Int. J. Numer. Anal. Methods Geomech. 30 (6), 501-527.

Stark, T.D., Olson, S.M., 1995. Liquefaction resistance using CPT and field case histories. J. Geotech. Eng. ASCE 121 (12), 856-869.

Teh, C.I., Houlsby, G.T., 1991. An analytical study of the cone penetration test in clay. Geotechnique 41 (1), 17-34.

Thevanayagam, S., Ecemis, N., 2008. Effects of permeability on liquefaction resistance and cone resistance. Geotechnical Earthquake Engineering and Soil Dynamics IV Congress. ASCE Geotechnical Special Publication. 181.

Thevanayagam, S., Martin, G.R., 2002. Liquefaction in silty soils - screening and remediation issues. Soil Dyn. Earthq. Eng. 22, 1034-1042.

Youd, T.L., et al., 2001. Liquefaction resistance of soils: summary report from the 1996 NCEER and 1998 NCEER/NSF workshops on evaluation of liquefaction resistance of soils. J. Geotech. Geoenviron. Eng. ASCE 127 (10), 817-833.

Zlatovic, S., Ishihara, K., 1997. Normalized behavior of very loose non-plastic soils: effects of fabric. Soils Found. 37 (4), 47-56. 